\title{
Peer instruction to address alternative conceptions in Einstein's special relativity
}

\author{
Manuel S. Alvarez-Alvarado*1,20, Cesar Mora ${ }^{1}$, Cesar B. Cevallos-Reyes ${ }^{3}$ \\ ${ }^{1}$ Centro de Investigación en Ciencia Aplicada y Tecnología Avanzada del Instituto Politécnico Nacional, Ciudad de México, \\ México \\ ${ }^{2}$ Facultad de Ingeniería Eléctrica y Computación, Escuela Superior Politécnica del Litoral, Guayaquil, Ecuador \\ ${ }^{3}$ Universidad Técnica de Manabí, Departamento de Ciencias Básicas, Portoviejo, Ecuador
}

Received on January 12, 2019; Accepted on February 20, 2019.

\begin{abstract}
In education, decades have been spent investigating what kind of beliefs and attitudes students may have in relation to learning. The relevance of these lies on the implications that it brings concerning students' alternative conceptions. This research focuses on the inclusion of Peer Instruction (PI) as a methodology to address the alternative conceptions in Einstein's special relativity. PI was selected since there is evidence that it has an impact on the academic performance of the students, however, concerning the topic of relativity, it has not been previously proposed. Alternative Conception Einstein's Special Relativity Test (ACESRT) is proposed to determine students' alternative conceptions. The sample for this study consisted of 25 high school students from Ecuador. In none of this level, students study Einstein's special relativity, nevertheless, in the current year a special course with senior students (picked randomly) was open in which the topic was considered in their academic curriculum. In the first lecture, the students filled a survey to get a notion of their beliefs and attitudes. Then a pre-test (ACESRT) take place, with a view getting information of alternative conceptions that students may have. Later, lectures following PI were given. At the end, to measure PI impact on students' attitudes, beliefs and alternative conceptions the students filled again a survey, followed by post-test (ACESRT). The results were statistically analyzed, and they reveal that PI has a strong impact on students' beliefs and attitudes. Furthermore, the methodology has the potential to address the alternative conception in concepts related to the topic Einstein's special relativity.
\end{abstract}

Keywords: Attitudes, Alternative Conceptions, Beliefs, Peer Instruction, Special Relativity.

\section{Introduction}

Throughout history, man has faced great changes in science. In the mid-nineteenth century, it was thought that Physics was booming and that anything was possible to explain by using Newton's laws. However, a single experiment would shatter the known laws at that time, and thus the beginning of a new era for Physics was born, where grand scientists revolutionized the world with their theories such as Lorentz, Einstein, and others. In the last decade, North American high schools have begun to incorporate modern physics in the curricula, but this becomes a challenge when the special relativity of Einstein is the topic of study.

Einstein's special relativity issue has caused controversy as to whether it should be included or not at the high school. Arriassecq and Greca state [1]:

"...the Special Theory of Relativity (STR) is an important issue and should be incorporated into the curricula of Physics in high school cycle. However, it appears that lack a deep understanding of the concepts relevant to correctly interpret the STR and its implications, despite

*Correspondence email address: manuel.alvarez.alvarado@iee.org having received formal instruction in the subject" This statement agrees with the one given by Pérez and Solbes $[2]$.

In recent decades Ostermann and Moreira [3] proposed to renew Physics Curriculum, by taking the following measures: 1) to arouse curiosity in students and help them to recognize that physics has an important application in daily life; 2) to the present the concepts of physics of the last century up to nowadays; not stop in 1900; 3) using modern physics as motivation toward science careers. Although these measures are a pathway to update the Physics Curriculum, these were strongly criticized for the following reasons [4]: firstly, there is a lack of advantage in the use of classical physics to explain modern physics. For instance, while in classical physics the speed of a particle is determined in terms of time and position, in quantum mechanics the speed of a particle is mainly defined by its wavelength, so the criterions applied in classical physics may not necessarily be applied to modern physics. Secondly, the concepts required to understand modern physics are not so easy to understand for high school students. For example, the following question will blow up the head of some high school students: "If what we see is the light that objects reflect, then, what we 
would see if we travel in a spaceship that moves at speed of light?". Thirdly, there is a limitation of modern Physics experiments development.

The relativity theory involves high domain of concepts related to time, space and mass and it cannot be interpreted as classical Physics. Now, this fact becomes more complex when dealing problem-solving, which according to Gagne [5] is the intellectual ability to the highest level. Moreover, the theory of learning have several intellectual abilities, but particularly problem-solving is the intellectual ability to the highest level [6-7]. This leads us to reconsider because teachers must keep in mind that action concepts and theorems of action affect problemsolving and is part of the teacher's task to determine them and have schemes to promote change.

On the other hand, the Physics Department of Harvard University, present data to work for ten years with Peer Instruction in courses in calculus and introductory physics for undergraduate students, with positive results, as the student manages to have a strength in conceptual reasoning and problem solving, these data were published by Crouch and Mazur [8]. In addition, other factors to consider are the beliefs and attitudes that the students have with a view to learn the subject. The beliefs and attitudes in education are closely related to the misconception as shown in recent studies [9-12].

Given the above, it is possible to state that problem solving is the hardest part to achieve in the learning process and it is essential to eliminate the alternative conceptions. Nevertheless, this requires an adequate methodology and this study presents Peer Instruction as one solution to this problem focused in the field of special relativity of Einstein, considering the fact of beliefs and attitudes of the students. The research is aimed at researchers in education and physics teachers with a view to giving them an improvement in the teaching-learning process in the stated topic.

The purpose of this study is to determine, the effect of peer instructions in the academic performance, beliefs and attitudes of the students, with a view to addressing the alternative conceptions in the topic of Einstein's special relativity. The hypothesis are as follows:

- H1: Peer Instruction as a teaching methodology help to address the alternative conceptions in Einstein's special relativity.

- H01: Peer Instruction as a teaching methodology has no effect to address the alternative conceptions in Einstein's special relativity.

The rest of the paper is structured as follows: Section 2 describes the relation between student's beliefs, attitudes and alternative conceptions. Section 3 presents the impact of Peer Instruction in teaching and learning process. In Section 4, the methodology used in this research is given. Section 5 presents the results and discussion. Finally, in Section 6 the conclusions and ideas for future research are given.

\section{Beliefs, Attitudes and Alternative Conceptions}

From the point of view of cognitive psychology, processing information is the main determinant of our emotions and behaviours since they largely determine our way of perceiving the world [13]. Some beliefs or attitudes are very stable and tend to have them turned on all the time. These usually are acquired in childhood, while still being formed and modified throughout our entire lives and we can learn to get rid of us hurt and replace them with more convenient. The beliefs and attitudes are not permanent, that is, many of them are activated or deactivated, depending on the circumstances. These memories preferentially perceive things that match with preconceived ideas. Regarding, teaching-learning process, teachers develop their own attitudes, beliefs, and expectations and these can influence the understanding of students. For that reason, all teaching methodologies are based on psychological models, which are briefly described in [14]. There is significant evidence that students who follow a traditional teaching, as a result, they show scarcely little meaningful learning. Due to this fact, they are not able to develop positive attitudes towards science and learning and on this lies the relevance the study students' beliefs and attitudes.

On the other hand, the term alternative conceptions refer to ideas that people have, which are inconsistent with scientifically acceptable ideas. The conceptions not only depend on the individual, it also depends on the environment that includes the attitudes, beliefs, feelings, emotions and situations. Focusing on Solving problems of special relativity, it involves the application of concepts and sometimes these concepts are "distorted" by the students. This happens because they already read or watched a video or just listen to talk about the topic. The core of an alternative conception lies in the theory of the conceptual fields. This is defined as an informal and heterogeneous set of problems, situations, concepts, relationships, structures, contents and operations of thought, connected to each other and probably intertwined during the acquisition of information. The theory of conceptual fields is based on key principles, key concepts and key question that leads to different situations depending on the explicative mechanism. Then, the individual codes the information in his own language, and accept the concept as true, even if this, not the right one. In Physics, several studies have been developed in different topic areas. Most of the studies of alternative conceptions and the recognition of conceptual fields refers to classical physics, while for modern physics there are limited studies [15-18]. Hence, there is need to develop a study on modern physics, to enhance the teaching-learning process giving relevance to this research since is focus on special relativity. 


\section{Peer Instruction}

There are different teaching methodologies; however, one of the most current and used today mainly in American universities is the Peer Instruction (PI). According to Mazur [19], PI is an instructional method in which the students study as groups of two or three rather than alone. Instead of presenting the level of detailed covered in the textbook or lecture notes, it consists of many brief presentations on key points. There is a wealth of evidence that peer learning and teaching is extremely effective for a wide range of goals, content, and students of different levels and personalities.

PI involves heuristic instruction [20] with concept test that allows the student to develop his knowledge. The methodology starts with a brief lecture on a determined topic. Next, a multiple-choice conceptual question related to the lecture is given. The student must give an answer and based on the percentage results (this is done usually using clickers, however nowadays there is online software that helps with this) the professor has three options:

1. If the percentage of correct answer is less than $30 \%$, then the concept is reviewed.

2. If the percentage of correct answer is between $30 \%$ and $70 \%$ then, peer discussion follows, and the student has the chance to re-enter his answer and finally the professor give the answer with a brief explanation.

3 . If the percentage of correct answer is more than $70 \%$ then the professor gives the answer with a brief explanation and can continue with the next topic.

The results of using this methodology are vast. For instance, in 2001 Crouch and Mazur [8], reported data from ten years of teaching with PI in the calculus and algebrabased introductory physics courses for non-majors. Their results indicated that student's mastery of both conceptual reasoning and quantitative problem solving increased by implementing PI. They also found that 155 students taught with PI in spring 2000 showed better performance than 178 students taught traditionally, averaging 7.4 out of 10 compared to 5.5 out of 10 . Furthermore, the implications of using PI does not stay in student performance, since in recent years in China, [21] reported using PI has positive changes in students' attitudes and beliefs.

At this point, there is sufficient evidence [22-24] to state that PI allows a better performance in student learning than the traditional methodology. However, none of these studies states about the alternative conception of the student and the application of PI in the topic of special relativity.

\section{Methodology}

\subsection{Research participants}

This research is developed in a non-governmental high school. The age of students is between 16 to 17 . The study was carried out with the participation of 25 senior students (10 girls and 15 men) from an Ecuadorian high school located in Tosagua city, Manabí province. A quasi-experimental type design was used with a pre-testintervention-post-test scheme with intact groups.

\subsection{Students beliefs and attitudes questionnaire}

Within the line of research presented, there are several works, nevertheless, one of great relevance is the one presented by Hongsa- Ngiam [25]. This research presents several instruments (questionnaires), based on high impact research, such as those of Perry [26] and Schommer-Aikins [27]. The instrument allows to determine the relationship between teacher's beliefs and attitudes about teaching and learning Physics, and the relationships between the beliefs and attitudes of their students with goals and motivation to learn Physics.

In 2006, Hackling said that the work is of great interest for the training of teachers in the teaching of physics, because learning is linked to beliefs and attitudes for both, teachers and students [25]. Furthermore, HongsaNgiam concludes about his work that improvements can be obtained in the teaching-learning process of physics if one has the appropriate attitudes and beliefs [25]. The research aims to determine the student's beliefs and attitudes when they study the topic of special relativity by the employment of the instruments developed by Dr. Hongsa-Ngiam. A point of interest is that Likert scale is used on this questionnaire. The questionnaire consists of 36 questions related to a total of five beliefs and four attitudes. Table 1 and Table 2, indicate the propositions of the questionnaire categorized by belief and attitude, respectively. The propositions of the questionnaire appear in order defined by the number given in the tables. The results are polarized, that is, towards one of the two extremes the posture was negative or positive; this indicates that most students answer in $4+5$ (agree + strongly agree) or $1+2$ (disagree + strongly disagree). A significant percentage was also obtained for option 3 (indecisive).

\subsection{Alternative conceptions Einstein's Special Relativity Test}

This test is called ACESRT and it allows to evaluate student's academic performance in the topic of special relativity. Each question has assigned an alternative conception with a concept and a theorem in action to address. This is presented in Table 3 . 
Table 1: Student's Beliefs grouped into Categories According to the Propositions of the Questionnaire.

\begin{tabular}{|c|c|}
\hline Belief & Questionnaire propositions \\
\hline \multirow{3}{*}{$\begin{array}{l}\text { Learning the concepts of physics } \\
\text { without giving much interest to the } \\
\text { mathematical part }\end{array}$} & 5. I must remember as many facts, laws and equations as possible in Einstein's special relativity. \\
\hline & 29. To get good grades in physics you must understand the ideas and remembering the facts \\
\hline & 33. Mathematics is not the main difficulty in learning physics, it is the theory itself. \\
\hline \multirow[t]{6}{*}{$\begin{array}{l}\text { The knowledge should be given by } \\
\text { the instructor }\end{array}$} & $\begin{array}{l}\text { 8. Discussing Einstein's special relativity ideas with other students does not help me understand } \\
\text { them. }\end{array}$ \\
\hline & 15. The instructor should listen to the class opinions. \\
\hline & 16. The instructor should explain each topic in detail. \\
\hline & $\begin{array}{l}\text { 20. My understanding in Einstein's special relativity mainly depends on how well I am taught } \\
\text { by my instructor. }\end{array}$ \\
\hline & $\begin{array}{l}\text { 21. In a lecture session, I take notes by writing down exactly what the instructor says and what } \\
\text { he writes on the board. }\end{array}$ \\
\hline & 22. I prefer to practice with the exercises that are similar to the examples given by the instructor. \\
\hline \multirow{3}{*}{$\begin{array}{l}\text { Learning for the development of } \\
\text { experiments }\end{array}$} & 13. Laboratory work in Einstein's special relativity is relevant for me. \\
\hline & 14. Experiments help me to understand Einstein's special relativity. \\
\hline & 35. The main purpose of laboratory work is to verify physics concepts and laws. \\
\hline \multirow{3}{*}{$\begin{array}{l}\text { Application and connection with } \\
\text { the world }\end{array}$} & 1. I don't want to study Einstein's special relativity because it is not relevant in my life. \\
\hline & $\begin{array}{l}\text { 2. I want to study Einstein's special relativity because it helps me to understand the world. } \\
\text { 11. Physics instruction must relate to everyday experiences, so we can see how it affects us in } \\
\text { our daily lives. }\end{array}$ \\
\hline & 36. Learning Einstein's special relativity is very important for the development of technology. \\
\hline \multirow[t]{3}{*}{$\begin{array}{l}\text { Grades are more important than to } \\
\text { learn }\end{array}$} & $\begin{array}{l}\text { 9. I just want to get a good grade and I am not interested in understanding Einstein's special } \\
\text { relativity ideas. }\end{array}$ \\
\hline & 26. If I work hard I will get good grades in physics. \\
\hline & 0 . I must be an obedient student in class to get good grades. \\
\hline
\end{tabular}

Table 2: Student's Attitudes Grouped into Categories According to the Propositions of the Questionnaire.

\begin{tabular}{|c|c|}
\hline Attitude & Questionnaire propositions \\
\hline \multirow{4}{*}{$\begin{array}{l}\text { Confidence in the } \\
\text { construction of his } \\
\text { own knowledge }\end{array}$} & 3. I have been required to study Einstein's special relativity by other people. \\
\hline & 7. It is important that I try to make sense of Einstein's special relativity concepts and really understand them. \\
\hline & $\begin{array}{l}\text { 10. Lecturing and giving notes are not the most important activities in the Einstein's special relativity lecture, } \\
\text { since I can read and understand in a better way the theory involved in the topic of study }\end{array}$ \\
\hline & 9. I need to learn by myself without the guidance from the instructor. \\
\hline \multirow{3}{*}{$\begin{array}{l}\text { Personal and } \\
\text { professional } \\
\text { motivation }\end{array}$} & . Studying Einstein's special relativity will help me with my career. \\
\hline & $\begin{array}{l}\text { 24. Physics is a subject not only for people who studies engineering, since it can be applied to different areas } \\
\text { of the sciences. }\end{array}$ \\
\hline & 34. In a lecture I prefer examples applicable to different careers \\
\hline \multirow[t]{4}{*}{$\begin{array}{lll}\text { Positive interest in } \\
\text { learning }\end{array}$} & $\begin{array}{l}\text { 6. Passing exam is not my biggest concern about studying Einstein's special relativity, since I want to learn } \\
\text { because is interesting. }\end{array}$ \\
\hline & $\begin{array}{l}\text { 12. I need some opportunities to discuss Einstein's special relativity ideas with my classmates to help me } \\
\text { understand physics. }\end{array}$ \\
\hline & $\begin{array}{l}\text { 18. The instructor should let us work on problems and exercises in small groups to help us learn physics. } \\
\text { 25. If I remember more facts and laws related with special relativity, then I will be able to develop different } \\
\text { problems in the topic. }\end{array}$ \\
\hline & 31. I always have some questions to ask or discuss with the instructor. \\
\hline \multirow[t]{3}{*}{ Effort in learning } & 17. The Einstein's special relativity lectures should be enjoyable. \\
\hline & $\begin{array}{l}\text { 23. I use my own words to summarize concepts from texts and lectures in Einstein's special relativity topic. } \\
\text { 27. If you are not a clever student you but if I put effort I will get good grades in physics. }\end{array}$ \\
\hline & \\
\hline
\end{tabular}

\subsection{Teaching strategy}

The instructional task used for this study is Einstein's special relativity, in which 18 hours of class were used. In the first lecture, to get information about the attitudes and beliefs of the students, the questionnaire of [25] was applied; the time for this task was 30 minutes. Then, a pre-test (ACESRT) took place with a view to get information about alternative conceptions that students have on the topic; the students had 45 minutes for this task. Later, a lecture following PI was applied.

Peer Instruction was implemented by using four key concept tests, which is a question that contains multiple choice answers (only one of them is correct). The key concept tests are employed in a period of 90 minutes, breaking the class into six sections of 15 minutes. The first 5-7 minutes of each section were used to introduce the ideas concerning principles of relativity. For instance, what happens if something travels close to speed of light? To answer this question there is no need the use of mathematical formulations, it is more about to understand the time dilation and space crunch concept. Later, the key concept test takes place and the students have one minute to determine the right answer. The students select an answer by using an electronic device with Wi-Fi connection (this could be cell phone, laptop, tablets, 
Table 3: Alternative Conception, Concepts and Theorems in Action to Address.

\begin{tabular}{|c|c|c|c|}
\hline Question & Alternative conception & Concepts in action & Theorems in action \\
\hline 1 & $\begin{array}{l}\text { Students may relate relativity } \\
\text { with some Einstein's experiment }\end{array}$ & Epistemology & $\begin{array}{l}\text { The history of the evolution of Physics give ideas for } \\
\text { future research }\end{array}$ \\
\hline 2 & $\begin{array}{l}\text { Students may not conceive space- } \\
\text { time as one thing }\end{array}$ & Space-time geometry & $\begin{array}{l}\text { Einstein's special relativity is based on the Lorentz's } \\
\text { transform }\end{array}$ \\
\hline 3 & $\begin{array}{l}\text { Students may have confusions } \\
\text { with inertial and non-inertial } \\
\text { frame }\end{array}$ & Inertia & $\begin{array}{l}\text { Given an inertial reference system, a second reference } \\
\text { system will be non-inertial when describing accelerated } \\
\text { motion with respect to the first. }\end{array}$ \\
\hline 4 & $\begin{array}{l}\text { Students may not know the au- } \\
\text { thor of special relativity }\end{array}$ & Epistemology & $\begin{array}{l}\text { The scientists inspire others to continue with the con- } \\
\text { struction of knowledge }\end{array}$ \\
\hline 5 & $\begin{array}{l}\text { Students may think that the } \\
\text { speed of light can vary }\end{array}$ & Light speed & $\begin{array}{l}\text { Light is speed has a constant value no matter the } \\
\text { reference frame }\end{array}$ \\
\hline 6 & $\begin{array}{l}\text { Students may believe that the } \\
\text { equation } E=m c^{2} \text { is one of the } \\
\text { postulates of special relativity }\end{array}$ & $\begin{array}{l}\text { Postulates of special rel- } \\
\text { ativity }\end{array}$ & $\begin{array}{l}\text { The postulates relate basically the space-time and light } \\
\text { and it does not mention the famous equation } E=m c^{2}\end{array}$ \\
\hline 7 & $\begin{array}{l}\text { Students may think that time } \\
\text { is same no matter the reference } \\
\text { frame }\end{array}$ & Time dilation & The time depends on the speed of the observer \\
\hline 8 & $\begin{array}{l}\text { Students may think that length } \\
\text { of a body is not related with its } \\
\text { speed }\end{array}$ & Space & $\begin{array}{l}\text { The length of a body depends on the speed of the } \\
\text { observer }\end{array}$ \\
\hline 9 & $\begin{array}{l}\text { Students may present difficulties } \\
\text { applying time dilation equation }\end{array}$ & Time dilation calculation & $\begin{array}{l}\text { Recognize that the time for the observer who is not } \\
\text { moving is greater than the one who is moving }\end{array}$ \\
\hline 10 & & & \\
\hline 11 & $\begin{array}{l}\text { Students may present difficulties } \\
\text { applying space crunch equation }\end{array}$ & Space crunch calculation & $\begin{array}{l}\text { Recognize that the length of a body that is moving is } \\
\text { greater than the one who is not moving }\end{array}$ \\
\hline 12 & & & \\
\hline 13 & $\begin{array}{l}\text { Students may have confusion ap- } \\
\text { plying the concept of relativistic } \\
\text { mass in classical equations }\end{array}$ & $\begin{array}{l}\text { Relation of the classical } \\
\text { equations with the rela- } \\
\text { tivistic ones }\end{array}$ & $\begin{array}{l}\text { It is not just about to replace equations and use them } \\
\text { without understanding the real meaning of them, espe- } \\
\text { cially with concept of relativistic mass }\end{array}$ \\
\hline 14 & $\begin{array}{l}\text { Students may not know how to } \\
\text { relate in a graph the relativistic } \\
\text { kinetic energy and the speed }\end{array}$ & Interpreting a chart & $\begin{array}{l}\text { Interpreting the graph and recognizing the physical } \\
\text { parameters involved allows us to establish an effective } \\
\text { scheme to establish a strategy and thus initiate the } \\
\text { resolution of the problem. }\end{array}$ \\
\hline 15 & $\begin{array}{l}\text { Students may think that there is } \\
\text { no application of special relativ- } \\
\text { ity }\end{array}$ & $\begin{array}{l}\text { Connection with the real } \\
\text { world }\end{array}$ & $\begin{array}{l}\text { The application of the theory is fundamental for the } \\
\text { development of science }\end{array}$ \\
\hline
\end{tabular}

etc.) The students need to access to Socrative webpage (www.socrative.com), so in that way they can access to the virtual classroom and select which they consider is the best answer. Socrative has the advantage of presenting the percentage of students that got the correct answer. If the percentage of correct answer is less than $30 \%$, then the concept is reviewed; If the percentage of correct answer is between $30 \%$ and $70 \%$ then, peer discussion follows, and the student has the chance to re-enter his answer and finally the professor give the answer with a brief explanation; If the percentage of correct answer is more than $70 \%$ then the professor gives the answer with a brief explanation and can continue with the next key concept test. It is relevant to highlight that none of the key tests contains questions that appears in the ACESRT.

In order to obtain students' academic performance a post-test (ACESRT) took place. In addition, with a view getting information about the impact of PI on the students' attitudes and beliefs, Hongsa-Ngiam's questionnaire [25] was employed again. These results were confronted in a statistical analysis to justify the hypotheses raised.

\subsection{Student "t" test}

In educational research of all types and levels, statistics allows to make inferences, check relationship between variables and reject or accept the hypotheses. For this research, the " $t$ " test was used to relate two different samples. The statistic refers to the means of the quantitative distributions of the different groups, that must meet the following conditions:

- The dependent variable must be numeric or at least presented in intervals.

- The dependent variable must follow a normalized or approximate normal distribution.

- Do not assume that the variances in both populations are equal.

The t-test contrasts the mean of two different populations. For every population a different action is executed and based on this fact several hypotheses are formulated. There are two kinds of hypotheses: the null and alternative hypothesis. The alternative hypothesis assumes that some difference exists between the true mean $(\mu)$ and the comparison value $\left(m_{0}\right)$, whereas the null hypothesis assumes that no difference exists. The purpose of the 
one sample t-test is to determine if the null hypothesis should be rejected, given the sample data. The t-test brings the statistical value $P$ and based on this the null hypothesis is accepted or rejected. If $P$ is less or equal than 0.05 the null hypothesis is rejected, otherwise, the null hypothesis is accepted.

Due to the given circumstances, this statistical test is ideal for this research, since it uses small groups, belonging to the same student population without making distinctions in sex or age, maintaining normal distribution, and recording entrance and exit tests to the different study groups.

\subsection{Hake Factor and the Dellwo Model}

This factor allows differentiating the performances obtained by the students. The results of the pre- and posttests are related to the following formulation that defines the Hake factor:

$$
g=\left(\theta_{\text {post }}-\theta_{\text {pre }}\right) /\left(1-\theta_{\text {pre }}\right)
$$

where $\theta_{\text {post }}$ is the normalized number of question students answer correctly in the post-test and $\theta_{\text {pre }}$ is the normalized number of question students answer correctly in the pre-test.

Unfortunately, this classic assessment rule can lead to counterintuitive conclusions. The Hake model shows a general gain value over the sample, and this is fact becomes in his Achilles heel. That is, this generalization disregards the recurrence of correct answers, generating a wrong learning gain. For a better understanding the following scenario is proposed: suppose we have a test that consists of 10 questions and whose marks has been assigned one point to each question. This test is used as before and after the executing the lecture. We randomly select a student " $\mathrm{x}$ ", who turns out to be responding correctly only the first six questions in his pre-test and in his post-test he answer correctly the last six questions. Using a Hake model, the learning gain result to be zero, which indicates that the student did not learn the subject at all, and this fact is false. Therefore, Dellwo [28] proposes a more accurate approach for the gain factor and is as follows:

$$
g=G-\omega L
$$

where $G$ is a normalized gain measuring the likelihood that a mistake on the group's pre-test is corrected on the post-test. Similarly, $L$ is a normalized loss measuring likelihood that a correct response on the group's pre-test is rendered incorrect on the post-test. The non-negative parameter $\omega$ is a renormalization factor dependent on the population's pre-instruction performance. Mathemat- ically, these terms can be calculated as [29]:

$$
\begin{aligned}
G & =\frac{\theta_{\text {pre }} \cap \mu_{\text {post }}}{\mu_{\text {pre }}}, \\
L & =\frac{\theta_{\text {pre }} \cap \mu_{\text {post }}}{\theta_{\text {pre }}}, \\
\omega & =\frac{\theta_{\text {pre }}}{1-\theta_{\text {pre }}}
\end{aligned}
$$

where $\mu_{\text {pre }}$ is the normalized number of questions students answer incorrectly on the pre-test, and $\mu_{\text {post }}$ is the normalized number of questions that students answer incorrectly on the post-test.

In order to get a conclusion by the employment of this factor, it uses the following ranges: high gain $(g \geq 0.7)$, medium gain $(0.7>g \geq 0.3)$ and low gain $(g<0.3)[28]$.

\subsection{Research design}

The research variables are:

- Independent variable: Peer Instruction

- Dependent variable: academic performance

In this design an experimental group (GE) is involved. The observations regarding the academic performance (as measure that indicates if the alternative conceptions in Einstein's special relativity were addressed) are $O_{1}$ and $\mathrm{O}_{2}$, where $\mathrm{O}_{1}$ corresponds to the measurement provided by the pre-test and $\mathrm{O}_{2}$ belongs to the measure recorded by the post-test. $X$ concerns the treatment, which involves the peer instruction. This design is summarized in the following scheme:

$$
G E \rightarrow \mathrm{O}_{1} \mathrm{XO}_{2}
$$

\section{Students' Beliefs \& Attitudes}

\subsection{Belief: Learning Physics' concepts without giving much interest to the mathematical part}

The results (Fig. 1) reveal that before applying PI, the $53.3 \%$ of students believed that in order to understand Physics, they needed to have strong bases on mathematics; the $34.7 \%$ of students were undecided and the rest of students $(12 \%)$ were in contrast position regarding this belief. Nevertheless, after applying PI, the student's belief changed and now the $80 \%$ of the students' belief that mathematics is not so relevant to understand Physics; the undecided students became less than $3 \%$ and the rest $(17.4 \%)$ still thinking that mathematics is needed to understand Physics.

It is relevant to recognize that Physics studies the physical processes that occur in nature and in the universe, and it can study them without knowing many mathematical formulations. In Physics, mathematics is a language that helps to quantify the phenomena. By the employment of PI, the students understood this criterion. 


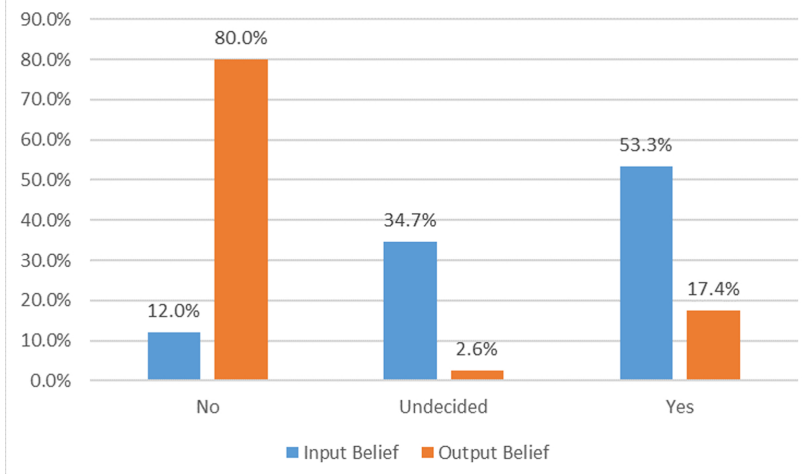

Figure 1: Percentage of students that belief: learning Physics' concepts without giving much interest to the mathematical part.

\subsection{Belief: Knowledge should be given by the instructor}

The results (Fig. 2) reveal that before applying PI, the $57.9 \%$ of students believed that the knowledge should be given by the instructor; the $16.7 \%$ of students were undecided and the rest of students (25.4\%) were in contrast position regarding this belief. Nevertheless, after applying PI, the student's belief changed and now $80.6 \%$ of the students belief that the instructor is not dependent from students' knowledge; the undecided students became $8.8 \%$ and the rest (10.6\%) still believing that the knowledge must come from the instructor.

The student is ultimately responsible for their own learning process. It is he who builds knowledge, and no one can replace him in that task. The importance given to the student's activity should not be interpreted as an act of discovery or invention, but in the sense that it is he who learns and, if he does not do it, nobody, not even the instructor, can do so. The teaching is totally mediated by the constructive mental activity of the student and by applying PI this fact was achieved.

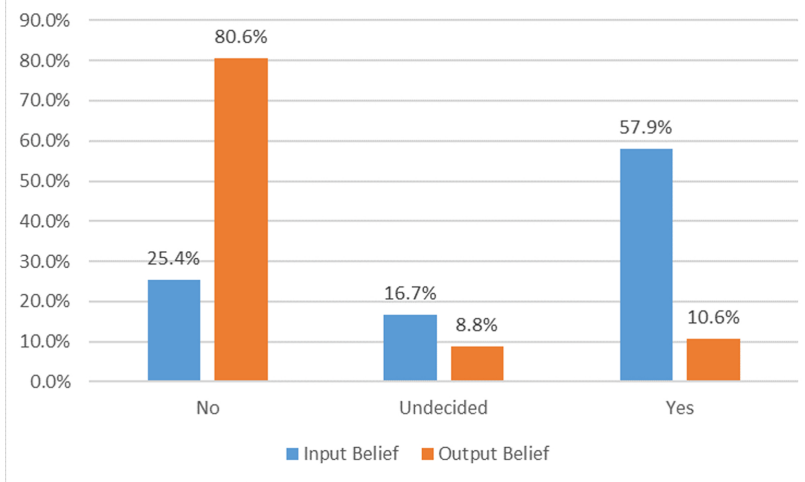

Figure 2: Percentage of students with the belief: knowledge should be given by the instructor.

\subsection{Belief: Learning for the development of experiments}

The development of experiments is essential in the teachinglearning process, moreover if the subject is Physics. Although the methodology does not present influence over this belief as shown in Fig. 3, the tendency of this belief is positive since most of the students (more than $70.0 \%$ for both cases) consider relevant the development of experiments for learning purposes.

\subsection{Belief: Physics must have an application and connection with the world}

The results (Fig. 4) reveal that initially the 3\%, $21.0 \%$ and $76.0 \%$ of the population has not, were undecided and has this belief, respectively. After applying PI, the undecided population reduced to $5.0 \%$ and that difference $16.0 \%$ started believing that there should be an application and connection with the world when they learn Physics.

PI has no significant impact on this belief. However, it helps to take a decision concerning the undecided students, since initially, the $21.0 \%$ of the population was undecided about this belief, nevertheless, after applying PI this percentage was reduced to $5.00 \%$.

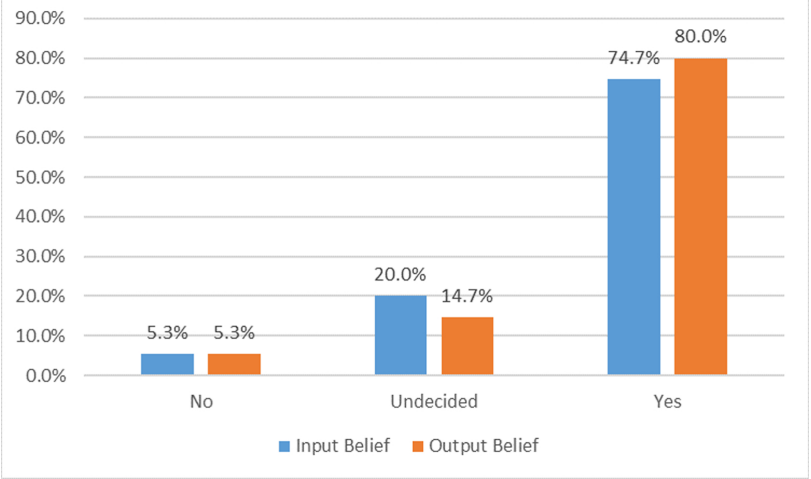

Figure 3: Percentage of students with the belief: learning for the development of experiments.

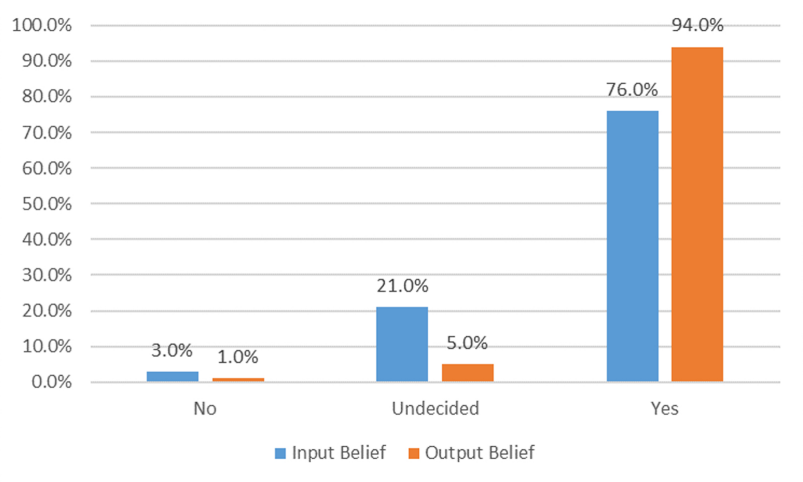

Figure 4: Percentage of students with the belief: Physics must have an application and connection with the world. 


\subsection{Belief: Grades are more important than to learn}

Fig. 5 shows that before applying PI the $47.3 \%$ of the students did not have this belief and it changed to $85.3 \%$; the number of undecided students was reduced from $12.0 \%$ to $9.3 \%$; and the $40.7 \%$ of the students who believed that grades are more important that to learn, also was reduced to $5.3 \%$. The main goal of any instructor is to teach not for a test, it is to teach in such a way that the student can be able to apply what he learned in daily life. The student must focus on learning, and good grades will come as a product of this fact. This was achieved by the employment of PI, as given in the results.

\subsection{Attitude: Confidence in the construction of his own knowledge}

The results (Fig. 6) reveal that before and applying PI, the $18.0 \%$ of students do not have the attitude of having confidence in the construction of his own knowledge. Before applying PI there were $37.0 \%$ undecided students; after applying PI, it reduced to $11.0 \%$; and finally before applying PI $45 \%$ of students were in contrast position regarding this attitude, however, after applying PI, the percentage increases to $71.0 \%$.

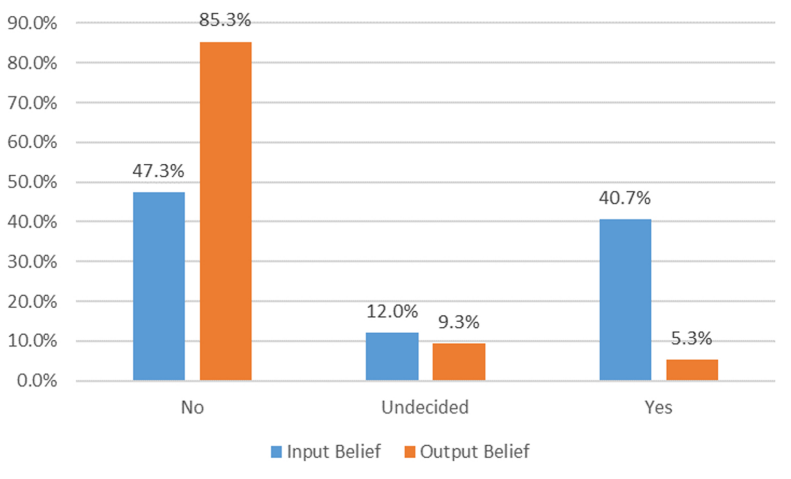

Figure 5: Percentage of students with the belief: grades are more important than to learn.

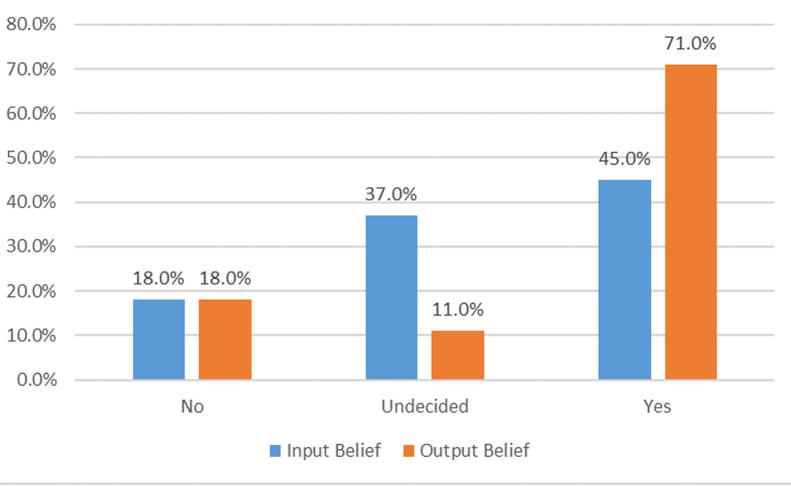

Figure 6: Percentage of students with the attitude: confidence in the construction of his own knowledge.
Nowadays, students have more resources and easy access to any information related to science and they can learn from it. The instructor must guide the students to construct their own knowledge, in such a way that students must not depend on the instructor to learn. It is not about teaching for a test, it is about teaching for daily life and with the employment of PI this can be achieved.

\subsection{Attitude: Personal and professional motivation}

The results (Fig. 7) reveal that before applying PI there were a high number $(45.7 \%)$ of students were undecided about this attitude and the rest $(54.3 \%)$ was sure about their personal and professional motivation. However, after the employment of PI the number of undecided students reduced in $25.7 \%$ and the difference become part of the student who possess this attitude.

Traditional education from the first years of studies to the postgraduate level has formed students who are commonly not very motivated and even bored with their way of learning. Students are forced to memorize a large amount of information and they tend to forget about much of what they have learned. If the students do not know the usefulness of what they learned, there is no point to learn and they will feel demotivated or undecided about the subject. However, PI influence to take a positive attitude concerning personal and professional motivation leading student to apply what they learn in daily life.

\subsection{Attitude: Positive interest in learning}

The results (Fig. 8) reveal that initially the $0.8 \%, 23.2 \%$ and $76.0 \%$ of the population has not, were undecided and has this attitude, respectively. After applying PI, these values changed to $2.4 \%, 19.2 \%$ and $78.4 \%$, respectively. It can be appreciated that PI has not significant impact on this attitude.

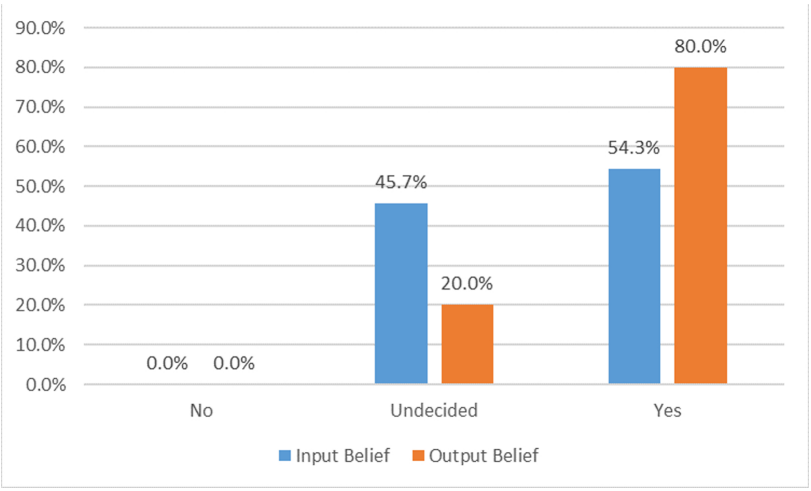

Figure 7: Percentage of students with the attitude: personal and professional motivation. 


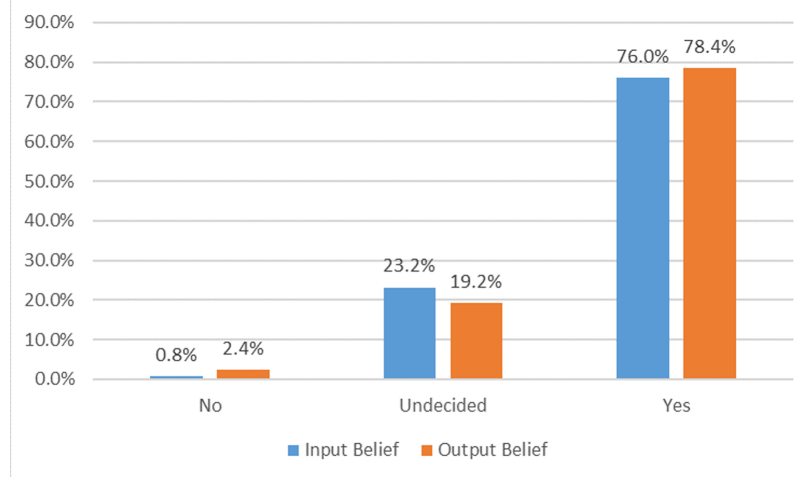

Figure 8: Percentage of students with the attitude: positive interest in learning.

\subsection{Attitude: Effort in learning}

The results (Fig. 9) reveal that initially the 3.0\%, 15.0\% and $82.0 \%$ of the students has not, were undecided and has this attitude, respectively. After applying PI, the first value remained the same and the other two values changed to $13.0 \%$ and $84.0 \%$, respectively.

It is not possible to determine if PI has an impact on this attitude since there is not a significant variation before and after applying PI. Nevertheless, it is assertive that there is a high number of students that put effort and show interest in learning.

\section{Special Relativity Alternative Conceptions}

\subsection{Students may relate relativity with some Einstein's experiment}

The first question given in the ACESRT involves a concept in action based on epistemology. The answer given by the students in the pre-test and post-test are shown in Fig. 10. For this question the right answer is "E". The results reveal that before applying the PI, $82.0 \%$ of the students relate relativity with some Einstein's experi-

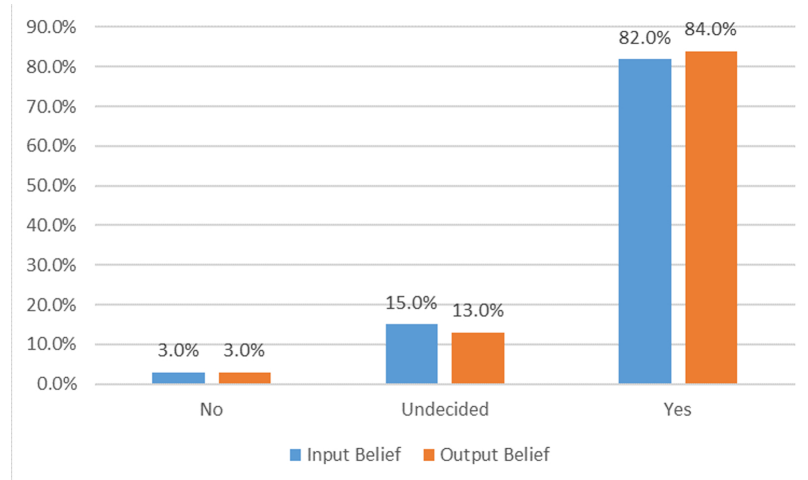

Figure 9: Percentage of students with the attitude: effort in learning.

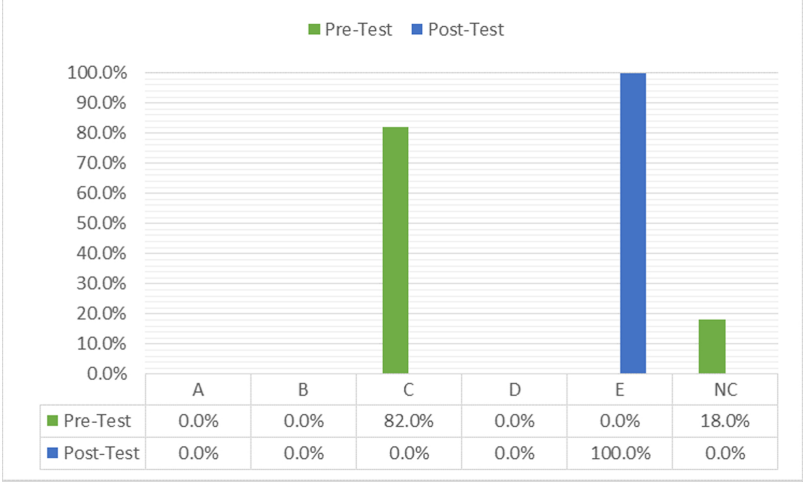

Figure 10: Students' answer for question 1 ACESRT.

ment and the rest (18.0\%) did not answer. Regardless, after applying PI the students change this misconception and now they relate relativity with Michelson and Morley experiment.

\subsection{Students may not conceive space-time as one thing}

The second question given in the ACESRT involves a concept in action based on space-time geometry. The answer given by the students in the pre-test and post-test are shown in Fig. 11. For this question the right answer is "B". The results reveal that initially, $88.0 \%$ of the students do not have any idea about the Lorentz transformation and the rest of the students $(12.0 \%)$ present a wrong idea about the topic. Nevertheless, after the lectures, students conceived space-time as one thing and they understood Lorentz transform since $80.0 \%$ of the students came with the right answer.

\subsection{Students may have confusions with inertial and non-inertial frame}

The third question given in the ACESRT involves a concept in action based on inertia. The answer given by the students in the pre-test and post-test are shown in Fig. 12. For this question the right answer is "B". The

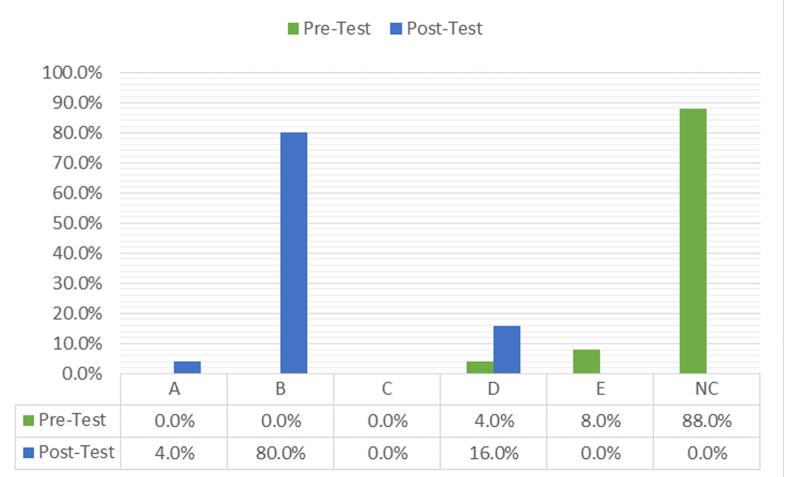

Figure 11: Students' answer for question 2 ACESRT. 


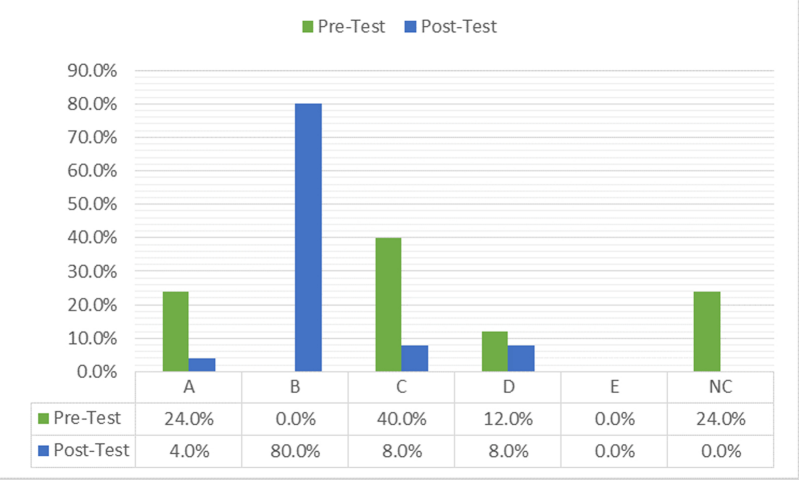

Figure 12: Students' answer for question 3 ACESRT.

results reveal that in the pre-test, $24.0 \%$ of the students think that an inertial system is the one with small mass, $40.0 \%$ of the students think that an inertial system is always in motion, $12.0 \%$ think that an inertial system is always at rest and the $24.0 \%$ do not know about the topic. Nevertheless, after the lectures, $80.0 \%$ of the students relate an inertial system like the one who follows Newton's law and the rest $(20.0 \%)$ present a wrong idea about it.

\subsection{Students may not know the author of special relativity}

The fourth question given in the ACESRT involves a concept in action based on epistemology. The answer given by the students in the pre-test and post-test are shown in Fig. 13. For this question the right answer is "A". In this question the answer was unanimous: "Einstein". There is something irony regarding their answer, although students know the author of special relativity, they do not have clear concepts about the topic such as space crunch and time dilation, moreover, about the Michelson and Morley experiment which strongly influenced to the development of the theory.

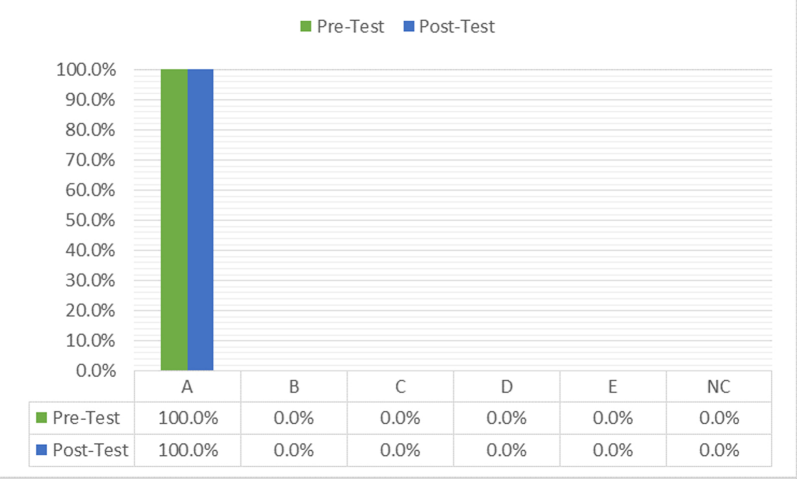

Figure 13: Students' answer for question 4 ACESRT.

\subsection{Students may think that speed of light can vary}

The fifth question given in the ACESRT involves a concept in action based on light speed. The answer given by the students in the pre-test and post-test are shown in Fig. 14. For this question the right answer is "C". The answers given by the students in the pre-test was varied. Nevertheless, after the lectures, the students clear their doubts and $96.0 \%$ of the students got the right idea, the speed of light is constant.

\subsection{Students may believe that equation $\mathrm{E}=\mathrm{mc}^{2}$ is one of the postulates of special relativity}

The sixth question given in the ACESRT involves a concept in action based on the postulates of special relativity. The answer given by the students in the pretest and post-test are shown in Fig. 15. For this question the right answer is "C". The answer given by the students in the pre-test was varied and most of them (48.0\%) do not have any idea about the topic. Regardless, after applying PI the students change this misconception and now the $72.0 \%$ has the right concept of Einstein special relativity postulate.

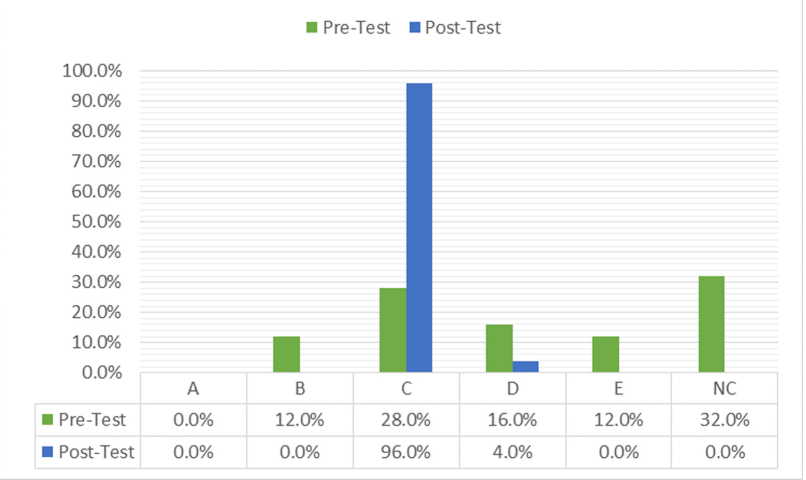

Figure 14: Students' answer for question 5 ACESRT.

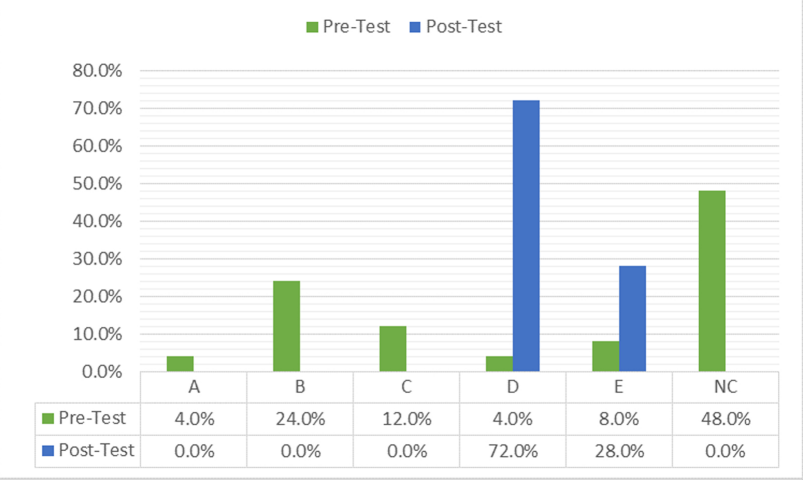

Figure 15: Students' answer for question 6 ACESRT. 


\subsection{Students may think that time do not vary}

The seventh question given in the ACESRT involves a concept in action based on time dilation. The answer given by the students in the pre-test and post-test are shown in Fig. 16. For this question the right answer is "B". The answer given by the students in the pre-test was varied. Regardless, after applying PI the students change this misconception and now the $84.0 \%$ associate time and observer's speed.

\subsection{Students may think that length of a body is not related with its speed}

The eighth question given in the ACESRT involves a concept in action based on space crunch. The answer given by the students in the pre-test and post-test are shown in Fig. 17. For this question the right answer is "B". The results reveal that in the pre-test, $16.0 \%$ of the students think the length of a body is always the same, $28.0 \%$ think that it depends on the speed of the observer, $28.0 \%$ think that depends on the direction of the movement, $4.00 \%$ think that always follows Newton's law and the rest $(24.0 \%)$ have no idea about the topic. Nevertheless, after the lectures, $72.0 \%$ of the students got the right relation between the length of an object and the speed of the observer.

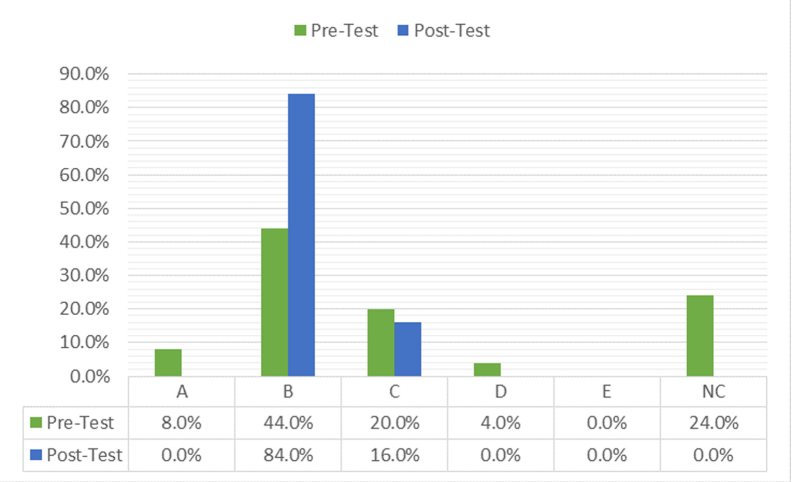

Figure 16: Students' answer for question 7 ACESRT.

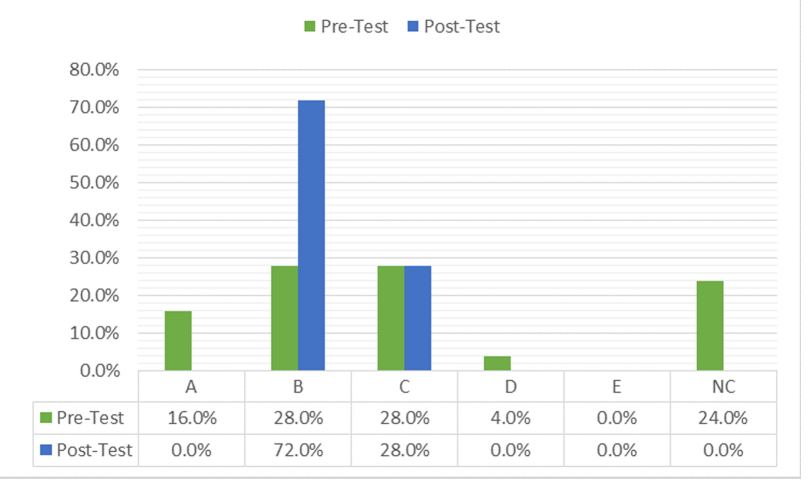

Figure 17: Students' answer for question 8 ACESRT.

\subsection{Students may present difficulties applying time dilation equation}

The ninth and tenth question given in the ACESRT involves a concept in action based on time dilation calculation. The answer given by the students in the pre-test and post-test for question 9 and 10 are shown in Fig. 18 and Fig. 19, respectively. For question 9 the answer is "A" and for question 10 is " $\mathrm{B}$ ". The results reveal that for question 9 in the pre-test, $60.0 \%$ of the students did not solve the problem, $16.00 \%$ of the students selected answer "A" which is correct and the rest $(32.0 \%)$ got the wrong answer. For question 10 in the pre-test, $72.0 \%$ of the students left the problem blank, $4.00 \%$ of the students selected answer "B" which is correct and the rest $(24.0 \%)$ got the wrong answer. To verify that students who got the right answer did not choose it arbitrarily, the instructor checked the process that they follow to get their answer. This fact reveals that students selected arbitrarily their answer since their process were wrong. Nevertheless, in the post-test the students showed a better performance that is $64.0 \%$ and $60.0 \%$ of the students got the right answer to question 9 and 10, respectively, following the right process to obtain their answers.

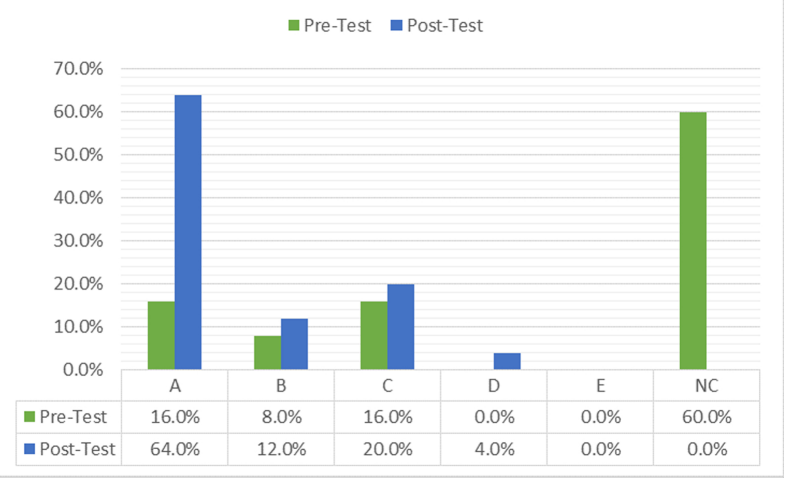

Figure 18: Students' answer for question 9 ACESRT.

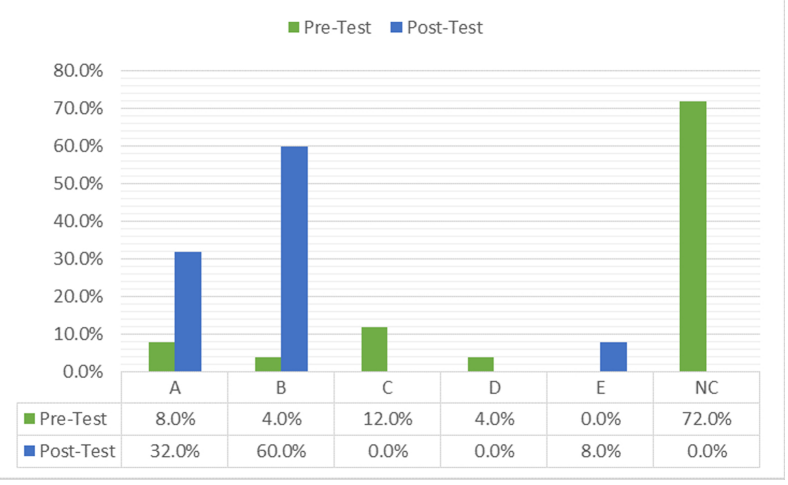

Figure 19: Students' answer for question 10 ACESRT. 


\subsection{Students may present difficulties applying space crunch equation}

The eleventh and twelfth question given in the ACESRT involves a concept in action based on time dilation calculation. The answer given by the students in the pre-test and post-test for question 11 and 12 are shown in Fig. 20 and Fig. 21, respectively. For question 11 the answer is " $\mathrm{E}$ " and for question 12 is " $\mathrm{D}$ ". The results reveal that for question 11 in the pre-test, $76.0 \%$ of the students did not solve the problem, $8.00 \%$ of the students selected answer "E" which is correct and the rest (16.0\%) got the wrong answer. For question 12 in the pre-test, $72.0 \%$ of the students left the problem blank, none of the students selected "D" which the correct answer and the rest is $(28.0 \%)$ got the wrong answer. To verify that students who got the right answer did not choose it arbitrarily, the instructor checked the process that they follow to get their answer. This fact reveals that students selected arbitrarily their answer since their process was wrong. Nevertheless, in the post-test the students showed a better performance that is $72.0 \%$ of the students got the right answer to both question 11 and 12, following the right process to obtain their answers.

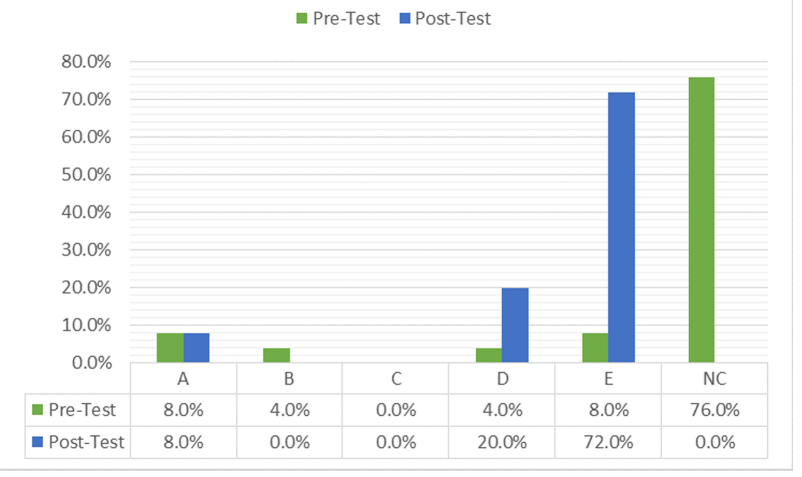

Figure 20: Students' answer for question 11 ACESRT.

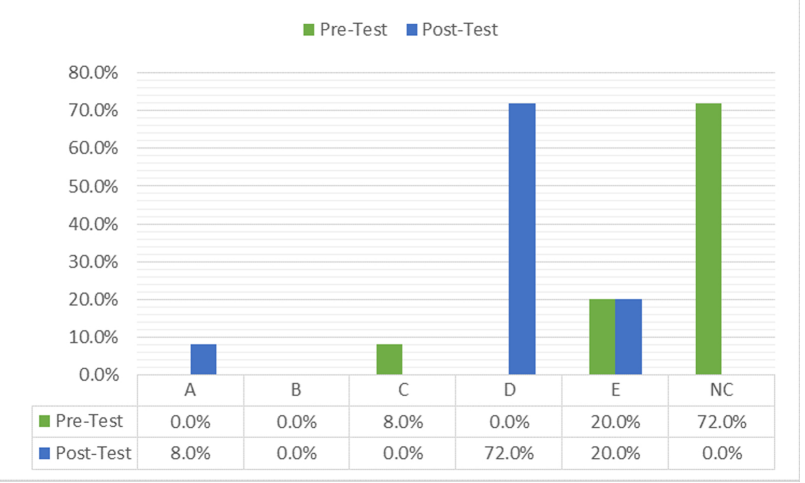

Figure 21: Students' answer for question 12 ACESRT.

\subsection{Students may have confusion applying the concept of relativistic mass in classical equations}

The thirteenth question given in the ACESRT involves a concept in action relation of the classical equations with the relativistic ones. The answer given by the students in the pre-test and post-test are shown in Fig. 22. For this question, the right answer is "A". The answer given by the students in the pre-test was varied and most of them $(60.0 \%)$ do not have any idea about the topic. Regardless, after applying PI the students change this misconception and now the $76.0 \%$ has the right concept regarding the relativistic mass.

\subsection{Students may not know how to relate in a graph the relativistic kinetic energy and the speed}

The fourteenth question given in the ACESRT involves a concept in action related with interpreting a chart. The answer given by the students in the pre-test and post-test are shown in Fig. 23. For this question, the right answer is " $\mathrm{A}$ ". $\mathrm{n}$ this question the $84.0 \%$ of the students did not answered and the rest (16.0\%) answered wrong. However, in the post-test the student showed a better performance that is the $72.0 \%$ of the students got the right answer. It is relevant to highlight that, although kinetic energy in

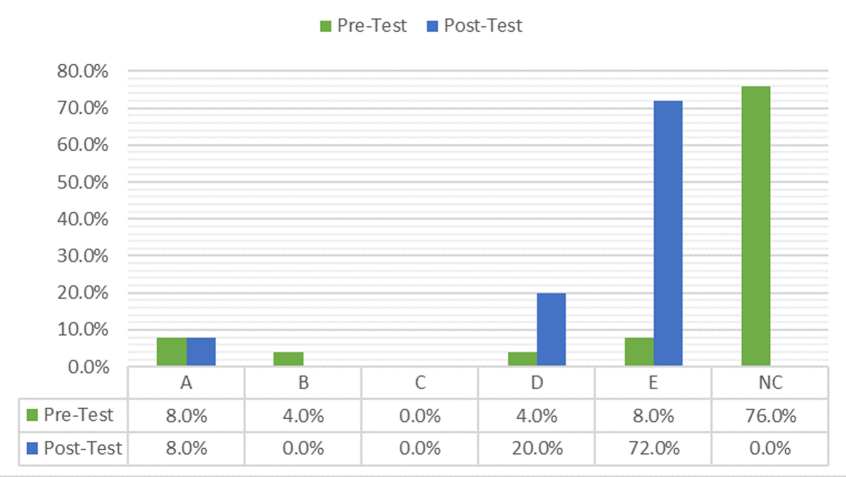

Figure 22: Students' answer for question 13 ACESRT.

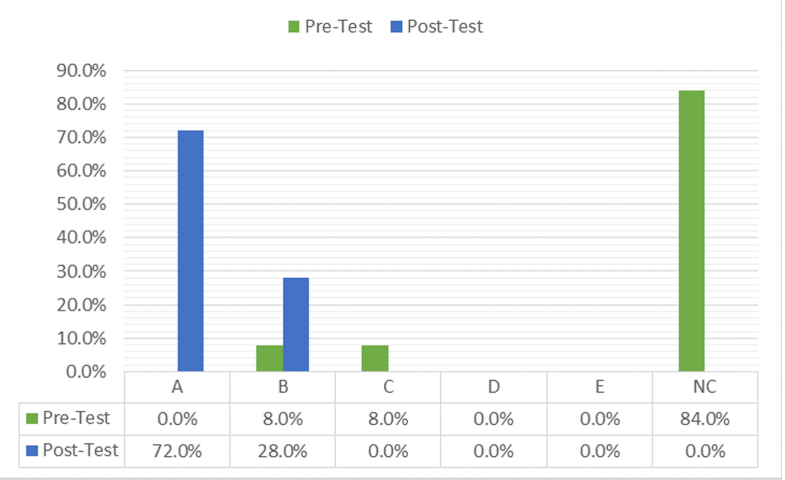

Figure 23: Students' answer for question 14 ACESRT. 
classical equation is directly proportional to the square of the object's speed, from the relativistic point of view there is a limit for the speed (speed of light) and due to relativistic mass, the kinetic energy must grow faster as it gets closer to the speed of light.

\subsection{Students may think that there is no application of special relativity}

The fifteenth question given in the ACESRT involves a concept in action related with connection with the real world. The answer given by the students in the pre-test and post-test are shown in Fig. 24. For this question, the right answer is "A". In this question, $48.0 \%$ did not answer this question, $36.0 \%$ of the students selected answer "A" and the rest $(16.0 \%)$ answered wrong. However, in the post-test the students clear their alternative conception and now the $96.0 \%$ of the students know an application of Einstein's special relativity. To give an application to what students learn is a pathway to motivation, this is what defines students' professional career.

\section{Statistical Analysis of the pre- and post-test}

In this section the data related with the pre- and posttest are used to verify the use of the " $t$ " test. The analysis starts presenting some descriptive statistics values obtained from the pre- and post-test as shown in

Table 4. Then, by using Excel 2013 a "t" test take place; the results are shown in Table 5 . It presents a $P$ value of $1.31064 \mathrm{E}-12$ which is less than 0.05 , therefore the null hypothesis is rejected in favor of the alternative hypothesis.

In this paper, the tests are standardized, such as those used in the original work of Hake (standardized tests of Physics for admission to university). That is, the test has 15 items, with 5 alternatives and with only one solution. Then the pre- and post-tests are compared with a view to getting results. The learning gain is obtained from the model given in section 4.6. Its calculation is as presented in Table 6.

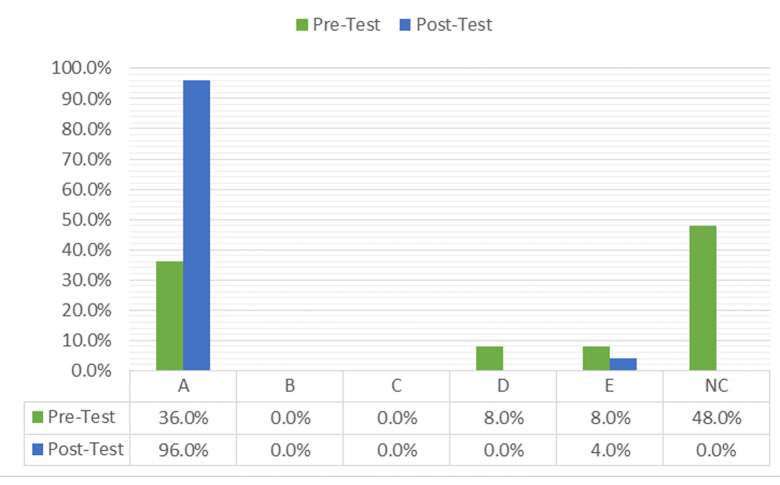

Figure 24: Students' answer for question 15 ACESRT.
Table 4: Descriptive Statistics of the Pre- and Post-Tests.

\begin{tabular}{lcc}
\hline Statistical Values & Pre-test & Post-test \\
\hline Participants & 25 & 25 \\
Mean & 2.76 & 10.72 \\
Median & 3 & 12 \\
Mode & 3 & 12 \\
Standard Deviation & 1.8321 & 2.1893 \\
Variance & 3.3567 & 4.7933 \\
Maximum & 7 & 15 \\
Minimum & 0 & 6 \\
Range & 7 & 9 \\
\hline
\end{tabular}

Table 5: t-test Results.

\begin{tabular}{lcc}
\hline & Variable 1 $\left(\mathrm{O}_{1}\right)$ & Variable 2 $\left(\mathrm{O}_{2}\right)$ \\
\hline Mean & 2.76 & 10.72 \\
Observations & 25 & 25 \\
Pearson Correlation & -0.0901645 & \\
t Stat & -13.3610218 & \\
t Critical one-tail & 1.71088208 & \\
$\mathbf{P}(\mathbf{T}<=$ t) two-tail & $\mathbf{1 . 3 1 0 6 4 E - 1 2}$ & \\
t Critical two-tail & 2.063898562 & \\
\hline
\end{tabular}

Table 6: Learning Gain Estimation using Hake and Dellwo Model.

\begin{tabular}{|c|}
\hline Input \\
\hline $\begin{array}{l}\text { Normalized average of correct answer pre-test } \\
\qquad \rightarrow \theta_{\text {pre }}=0.20\end{array}$ \\
\hline $\begin{array}{l}\text { Normalized average of correct answer post-test } \\
\qquad \theta_{\text {post }}=0.77\end{array}$ \\
\hline $\begin{array}{l}\text { Normalized average of number of questions students } \\
\text { answer correctly on the post-test and incorrectly on the } \\
\text { pre-test: }\end{array}$ \\
\hline$\theta_{\text {post }} \cap \mu_{\text {pre }}=0.10$ \\
\hline $\begin{array}{l}\text { Normalized average of number of questions students } \\
\text { answer incorrectly on the post-test and correctly on the } \\
\text { pre-test: }\end{array}$ \\
\hline$\theta_{\text {pre }} \cap \mu_{\text {post }}=0.23$ \\
\hline Output \\
\hline $\begin{aligned} G & =\frac{\theta_{\text {post }} \cap \mu_{\text {pre }}}{\mu_{\text {pre }}}=\frac{0.23}{0.27}=0.85 ; \quad L=\frac{\theta_{\text {pre }} \cap \mu_{\text {post }}}{\theta_{\text {pre }}}= \\
\frac{0.10}{0.20} & =0.50 ; \quad \omega=\frac{\theta_{\text {pre }}}{1-\theta_{\text {pre }}}=\frac{0.20}{1-0.20}=0.25\end{aligned}$ \\
\hline $\begin{array}{c}\text { Learning Gain } \\
g=G-\omega L=0.85-(0.25)(0.50) \rightarrow \mathbf{g}=\mathbf{0 7 3}\end{array}$ \\
\hline
\end{tabular}

\section{Conclusion}

This paper presents the impact of PI over the beliefs and attitudes of the students. In addition, the alternative conceptions with their respective concept and theorem in action were identified.

From the t-test, the $P$ value obtained was $1.31064 \mathrm{E}-12$ $(P<0.05)$ and there is enough evidence to reject the null hypothesis H01. Therefore, PI as a teaching methodology help to address the alternative conceptions in Einstein's special relativity. Moreover, the learning gain obtained following the Dellwo model is $0.73(g>0.7)$. Hence, PI brings a high gain learning, which opens a pathway for the inclusion of Einstein's special relativity topic in high school curricula.

The effectiveness of the teaching and learning Physics is one of the main concerns of educators around the globe. There is no doubt that beliefs and attitudes are 
important factors that affect students' learning strategies, furthermore, they influence in the alternative conceptions of the students. Therefore, alternative conceptions affect the teaching-learning process and it is part of the teacher to find them in order to succeed in the lecture.

\section{Supplementary material}

The following online material is available for this article: Annex 1: Student's beliefs and attitudes questionnaire $[25]$.

Annex 2: Alternative conceptions einstein's special relativity test (acesrt).

\section{References}

[1] I. Arriassecq and I. Greca, Rev. Electrónica Enseñanza las Ciencias 3, 2 (2004).

[2] H. Pérez and J. Solbes, Enseñanza las ciencias Rev. Investig. y Exp. didácticas 21, 1 (2003).

[3] F. Ostermann and M.A. Moreira, Enseñanza las ciencias Rev. Investig. y Exp. didácticas 18, 3 (2000).

[4] H. Pérez and J. Solbes, Enseñanza las ciencias Rev. Investig. y Exp. didácticas 24, 2 (2006).

[5] R.M. Gagne, The Conditions of Learning (Holt, Rinehart and Winston, New York, 1985), $1^{\mathrm{a}}$ ed.

[6] H. Gardner, Estructuras de la mente: la teoría de las inteligencias múltiples (Fondo de cultura económica, Mexico D.F., 2016), $1^{\mathrm{a}}$ ed.

[7] J.S. Hyde, S.M. Lindberg, M.C. Linn, A.B. Ellis and C.C. Williams, Science 321, 5888 (2008).

[8] C.H. Crouch and E. Mazur, Am. J. Phys., 69, 9 (2001).

[9] I. Abrahams, M. Homer, R. Sharpe and M. Zhou, Res. Sci. Technol. Educ. 33, 1 (2015).

[10] A. Çeti?n, An investigation of physics education doctoral dissertations made in Turkey between 2010 and 2015. Doctoral thesis, Siirt University, Siirt (2016).

[11] Z. Ghadiri, D. Noroozi and H. Fardanesh, Interdisciplinary Journal Of Virtual Learning In Medical Sciences, 6, 4 (2016).

[12] Ö. Keleş and S. Özsoy, Int. Electron. J. Elem. Educ. 1, 3 (2017).

[13] G. Maio and G. Haddock, The psychology of attitudes and attitude change (Sage, New York, 2014), $2^{\mathrm{a}}$ ed.

[14] M.S. Alvarez-Alvarado and F. Flores, Análisis de las creencias de los profesores sobre el aprendizaje de sus estudiantes y su actitud en la enseñanza de la física, de las universidades de la ciudad de Guayaquil. Master Thesis, Escuela Superior Politécnica del Litoral, Guayaquil (2015).

[15] D. McGrath, M. Wegener, T.J. McIntyre, C. Savage and M. Williamson, Am. J. Phys. 78, 8 (2010).

[16] Z. Tanel, J. Balt. Sci. Educ. 13, 4 (2014).

[17] M.S. Alvarez-Alvarado, Latin-American J. Phys. Educ. 11, 1 (2017).

[18] A. Kohnle, S. Mclean and M. Aliotta, Eur. J. Phys. 32, 1 (2010).

[19] E. Mazur and R.C. Hilborn, Phys. Today 50, 4 (1997).

[20] M.S. Alvarado-Alvarez and F. Urbano-Vaca, Rev. Bases la Ciencia 2, 3 (2017).
[21] P. Zhang, L. Ding and E. Mazur, Phys. Rev. Phys. Educ. Res. 13, 1 (2017).

[22] E.D. Kielt, S. de C.R. Da Silva and A.F. Miquelin, Rev. Bras. Ensino Física 39, 4 (2017).

[23] A.A.V.R. de Araujo and A.L. de Oliveira, Rev. Bras. Ensino Física 39, 2 (2017).

[24] M.G. Müller, I.S. Araujo, E.A. Veit and J. Schell, Rev. Bras. Ensino Física 39, 3 (2017).

[25] A. Hongsa-Ngiam, An investigation of physics instructors' beliefs and students' beliefs, goals and motivation for studying physics in Thai Rajabhat universities. Doctoral thesis, Edith Cowan University, Perth (2006).

[26] J. Barwise and J. Perry, J. Philos. 78, 11 (1981).

[27] M. Schommer and K. Walker, Res. High. Educ. 38, 2 (1997).

[28] D.R. Dellwo, J. Scholarsh. Teach. Learn. 10, 1 (2012) .

[29] A. Seyed Fadaei, A study about how students are able to analyze mechanics situation using Newton's laws. Doctoral thesis, Instituto Politécnico Nacional, Mexico D.F. (2015). 